\title{
Erratum to: Synthesis of silicate-1 monolith and its catalytic application
}

\author{
Xiaobing Yang ${ }^{1} \cdot$ Liuqing Huang ${ }^{1} \cdot$ Guiqing Du $^{1} \cdot$ Xuetao Luo $^{1}$
}

Published online: 22 December 2016

(C) Springer Science+Business Media New York 2016

\section{Erratum to: J Porous Mater}

DOI 10.1007/s10934-016-0327-4

Unfortunately, there is a typo in the name of the corresponding author. The name should be "Xuetao Luo", and not "Xuetao Lu". The name is correctly published with this erratum.

The online version of the original article can be found under doi:10.1007/s10934-016-0327-4.

Xuetao Luo

xuetao@xmu.edu.cn

1 Fujian Key Laboratory of Advanced Materials, College of Materials, Xiamen University, Xiamen 361005, China 